\title{
Graduate Student Literature Review: Detecting health disorders using data from automatic milking systems and associated technologies ${ }^{1}$
}

\author{
M. T. M. King ${ }^{2}$ and T. J. DeVries ${ }^{3}$ \\ Department of Animal Biosciences, University of Guelph, Guelph, ON, N1G 2W1, Canada
}

\section{ABSTRACT}

This review synthesizes a range of research findings regarding behavioral and production responses to health disorders and subsequent illness detection for herds using automatic (robotic) milking systems (AMS). We discuss the effects of health disorders on cow behavior and production, specifically those variables that are routinely recorded by AMS and associated technologies. This information is used to inform the resultant use of behavior and production variables and to summarize and critique current illness detection studies. For conventional and AMS herds separately, we examined research from the past $20 \mathrm{yr}$ and those variables recorded automatically on-farm that may respond to development of illness and lameness. The main variables identified were milk yield, rumination time, activity, and body weight, in addition to frequency of successful, refused, and fetched (involuntary) milkings in AMS herds. Whether making comparisons within cow or between sick and healthy cows, consistent reductions in activity, rumination time, and milk yield are observed. Lameness, however, had obvious negative effects on milk yield but not necessarily on rumination time or activity. Finally, we discuss detection models for identifying lameness and other health disorders using routinely collected data in AMS, specifically focusing on their scientific validation and any study limitations that create a need for further research. Of the current studies that have worked toward disease detection, many data have been excluded or separated for isolated models (i.e., fresh cows, certain lactation groups, and cows with multiple illnesses or moderate cases). Thus, future studies should (1) incorporate the entire lactating herd while accounting for stage of lactation and parity of each animal; (2) evaluate the deviations that cows

Received January 30, 2018.

Accepted May 6, 2018.

${ }^{1}$ Submitted to the 2019 ADSA Foundation Graduate Student Literature Review Competition (Production Division, $\mathrm{PhD}$ ) on June $5,2018$.

${ }^{2}$ Corresponding author: meagantmking@gmail.com

${ }^{3}$ Advisor (tdevries@uoguelph.ca). exhibit from their own baseline trajectories and relative to healthy contemporaries; (3) combine the use of several variables into health alerts; and (4) differentiate the probable type of health disorder. Most importantly, no model or software currently exists to integrate data and directly support decision-making, which requires further research to bridge the gap between technology and herd health management.

Key words: automatic milking, robotic milking, behavior, health management

\section{INTRODUCTION}

Rapid adoption of automatic (robotic) milking systems (AMS) for dairy cows is occurring worldwide. As of 2014, over 25,000 farms globally were using AMS (Barkema et al., 2015) and this number continues to grow. In Europe, this has been predominantly driven by growth in the Netherlands and Nordic countries, and in North America, Canada is the major domain of AMS use because of stable milk prices through supply management (Barkema et al., 2015). Benefits of AMS for farmers include reduced labor requirements and greater time flexibility, while cows benefit by having more freedom to control their time budgets (Jacobs and Siegford, 2012). Regarding health management, a key advantage of AMS is the availability of daily, cowlevel data that are collected by AMS and associated technologies. As a result, Tse et al. (2017) reported that, after transitioning to AMS, $66 \%$ of producers changed their health management strategy and $80 \%$ of producers found illness detection to be easier than before transitioning because of the AMS and associated health-monitoring software. On the other hand, some of the main barriers preventing adoption of technology by dairy producers are that technologies are not easy to use, they provide too much information without clear recommended action, and that their performance must be evaluated by independent research (Russell and Bewley, 2013; Borchers and Bewley, 2015).

Thus, there is a need to transform behavior and production data into timely, useful, reliable, and actionable information for producers. Not only should these 
data be collected by validated technologies, they must be incorporated into validated models and algorithms by combining the knowledge of field experience and science. Producers must adapt their management skills to become more technology-based as they spend more time viewing and interpreting data. Furthermore, farmers, advisors, and support staff must learn to interpret information correctly, and with this information, they can implement the proper herd management and corrective action needed to achieve success with AMS.

Therefore, this review summarizes research over the past $20 \mathrm{yr}$ pertaining to the effects of health disorders on behavior and productivity of dairy cows, and the resultant use of those variables to help detect disorders. However, because such a large focus has been placed on using milk quality variables, such as electrical conductivity, SCC, and color, to detect mastitis in previous research (Hogeveen et al., 2010; Rutten et al., 2013), this review will focus on using routinely collected behavior and production measures to detect locomotion and metabolic disorders such as lameness, hoof disorders, ketosis, subclinical ketosis (SCK), displaced abomasum (DA), metritis, and pneumonia, in addition to briefly discussing mastitis detection.

Literature search criteria consisted of a web-based search through Web of Science, using the following search terms as topics: "automated milking" or "automatic milking" or "robotic milking," and "dairy cow behavior" or "dairy cow production" or "dairy cow milk yield," as well as a search regarding health management and illness detection. Inclusion criteria were that the paper must have been published in or after 2000 and must report on data collected routinely by AMS, such as milk yield, milk quality, BW, and cow activity and rumination behavior as measured by leg pedometers or neck collars.

\section{EFFECTS OF HEALTH DISORDERS ON BEHAVIOR AND PRODUCTION}

The negative effects of health disorders have been well documented for conventional herds, but less is known about these effects in AMS herds. The general outcomes associated with lameness and illness are likely similar in loose-housing systems, regardless of milking equipment; however, the individualized and voluntary nature of milking in AMS could intensify the effects of and responses to illness, given that cows are not manually brought to a milking parlor at set intervals. Therefore, we have comparatively summarized the consequences of lameness and illness in conventional and AMS herds to report overall trends, similarities, and differences.

\section{Lameness: Associations with Behavior and Production in AMS and Conventional Herds}

Table 1 shows recent findings regarding associations of lameness with behavior and productivity in conventional and AMS herds in the past 2 decades. Regarding milk yield, lameness in both conventional and AMS herds has obvious negative impacts, whether comparing lame and sound cows or looking at changes leading up to diagnosis. However, there is no clear effect on rumination time or activity (Table 1 ). Researchers have reported lower milk yield to be associated with lameness in conventional herds (4 to $10 \mathrm{~kg} / \mathrm{d}$ lower than sound cows; Van Hertem et al., 2013) and AMS herds $(1.6 \mathrm{~kg} / \mathrm{d}$ lower than sound cows; Bach et al., 2007; King et al., 2017a); leading up to lameness, milk yield of lame cows declined by $4 \mathrm{~kg}$ in total over $14 \mathrm{~d}$ (Van Hertem et al., 2013). Lame cows in a conventional herd had numerically (but not statistically significant) lower milk yield compared with healthy cows (Steensels et al., 2017a) and there was no association between milk yield and gait score in an AMS herd, when the majority of cows had locomotion score of 2 or 3 out of 5 (Deming et al., 2013). Bicalho et al. (2008) conducted multiple analyses, using various study designs, to assess the impact of hoof horn lesions on milk yield in conventional herds. Because lame cows produced $3.2 \mathrm{~kg} / \mathrm{d}$ more milk than control cows in the first 3 wk of lactation, those authors then controlled for that early-lactation milk yield and found that lame cows actually produced 1.0 $\mathrm{kg} / \mathrm{d}$ less milk than control cows throughout lactation. The authors then matched 603 lame cows with 603 sound cows, again accounting for early-lactation milk yield, and found that lame cows produced $1.4 \mathrm{~kg} / \mathrm{d}$ less milk than control cows (Bicalho et al., 2008). Thus, milk yield may be greater in cows about to become lame $(1.1 \mathrm{~kg} / \mathrm{d}$ more milk before cows were diagnosed with lameness), but once diagnosed, their production drops to that of an average cow (Green et al., 2002), and it is important to consider the previous milk yield and lactation potential of a cow when considering her current milk production.

Some researchers have identified associations between lameness and rumination time in conventional and AMS herds. In some studies, lame cows spent less time ruminating than healthy animals in conventional systems $(-10 \%$ or approximately $40-50 \mathrm{~min} / \mathrm{d}$; Almeida et al., 2008; Van Hertem et al., 2013; Paudyal et al., 2017; Steensels et al., 2017a), whereas other researchers have observed no difference between lame and sound cows in conventional and AMS herds (Walker et al., 2008; King et al., 2017a). Before diagnosis of lameness or hoof disorders, researchers found that rumination 
time began to decline 3 to $5 \mathrm{~d}$ before diagnosis in a conventional herd by $\sim 50 \mathrm{~min}$ in total $(\mathrm{n}=25$; Paudyal et al., 2017). In an AMS herd, rumination time declined throughout the 2 -wk period before diagnosis by $\sim 40$ min in total, controlling for DIM and parity $(\mathrm{n}=15$; King et al., 2017b); the latter group also found that the ratio of night:day rumination time increased leading up to diagnosis. Alternatively, Van Hertem et al. (2013) reported lame cows to have greater daytime rumination, lower nighttime rumination, and a lower ratio of night: day rumination compared with sound cows in a conventional herd, and although not analyzed specifically, rumination time of lame cows declined before diagnosis.

With regards to activity, lame cows can be less active than healthy individuals. This has been demonstrated using data from neck collars to measure activity; differences have been seen in overall daily activity in conventional herds ( $-10 \%$; Steensels et al., 2017a), as well as activity overnight in AMS (Garcia et al., 2014; King et al., 2017a) and a conventional herd (Van Hertem et al., 2013). When assessed visually during specific observa- tion periods, lame cows were observed walking less often than sound cows in a conventional system (Walker et al., 2008). In contrast, King et al. (2017a) saw no differences in daily activity between lame and sound individuals, and King et al. (2017b) did not observe changes in activity in the 2 wk before hoof disorders diagnoses.

One might expect that overnight activity in AMS is related to milking activity and frequency. However, the increased nighttime activity for lame cows in AMS did not coincide with increased milking activity in 2 studies. Miguel-Pacheco et al. (2014) found that, compared with sound cows, lame cows not only visited the AMS less often overall 2.8 vs. 3.2 visits/d), they did so less between midnight and $0600 \mathrm{~h}$. Similarly, King et al. (2017a) reported lame cows in AMS to have a lower milking frequency overall 0.3 fewer milkings/d) and as a nighttime:daytime ratio. In the 2 wk before diagnosis of hoof disorders in AMS, milking frequency declined by 0.05 milkings/d, a total reduction of approximately 0.6 daily milkings during this period (King et al., 2017b).

Table 1. Associations of lameness with variables of interest in conventional and automatic milking system (AMS) herds

\begin{tabular}{|c|c|c|c|}
\hline Trial & Comparison(s) & Change(s) associated with lameness & Sample population \\
\hline Almeida et al. (2008) & Lame vs. sound & Rumination time $\downarrow$ & 16 cows, 1 farm \\
\hline Bicalho et al. (2008) & Lame vs. sound & Milk yield $\downarrow$ & 3,623 cows, 1 farm \\
\hline Singh et al. (2011) & Lame vs. sound & Milk yield $\downarrow$ & 163 cows, 1 farm \\
\hline Van Hertem et al. (2013) & $\begin{array}{l}\text { Lame vs. sound } \\
\text { Within lame cows }\end{array}$ & $\begin{array}{l}\text { Milk yield } \downarrow \\
\text { Activity ratio night:day } \uparrow \\
\end{array}$ & 118 cows, 1 farm \\
\hline Steensels et al. (2017a) & $\begin{array}{l}\text { Lame vs. other vs. healthy by } \\
\text { DIM }\end{array}$ & $\begin{array}{l}\text { Rumination time } \downarrow \\
\text { Activity } \downarrow \\
\text { Milk yield: no association }\end{array}$ & 704 cows, 1 farm \\
\hline Weigele et al. (2018) & Moderately lame vs. sound & $\begin{array}{l}\text { Activity } \downarrow \text { first hour after feed delivery or } \\
\text { pushup } \\
\text { Rumination time: no association }\end{array}$ & 389 cows, 17 farms \\
\hline Borderas et al. (2008) & High vs. low frequency visitors & NRS $\downarrow$ for cows visiting more AMS frequently & 256 cows, 8 farms \\
\hline Deming et al. (2013) & $\begin{array}{l}\text { Linear models with NRS } 1 \\
\text { to } 5\end{array}$ & $\begin{array}{l}\text { Milking frequency } \downarrow \\
\text { Milk yield: no association }\end{array}$ & 90 cows, 1 farm \\
\hline Garcia et al. (2014) & Lame vs. sound & $\begin{array}{l}\text { Activity in early morning/evening } \uparrow \\
\text { Activity unstable throughout the day } \\
\text { Teat cup attachment speeds unstable }\end{array}$ & 88 cows, 1 farm \\
\hline Miguel-Pacheco et al. (2014) & Lame vs. sound & $\begin{array}{l}\text { Rumination time } \downarrow \\
\text { AMS visits } \downarrow \text { overall and overnight } \\
\text { Refusals and fetches: no significance }\end{array}$ & 150 cows, 1 farm \\
\hline King et al. (2017a) & Lame vs. sound & $\begin{array}{l}\text { Milk yield, frequency, voluntary milkings and } \\
\text { refusals (i.e., no milking permission) } \downarrow \\
\text { Activity ratio night:day } \uparrow \\
\text { Rumination time, activity, and night:day } \\
\text { rumination ratio: no association }\end{array}$ & 1,184 cows, 41 farms \\
\hline
\end{tabular}

${ }^{1} \mathrm{NRS}=$ numerical rating score 
Other researchers have also observed lower milking frequencies (overall and voluntary) for lame cows in AMS herds compared with sound cows (Bach et al., 2007; Borderas et al., 2008). King et al. (2017a) also reported 0.2 fewer refused milkings per day and $2.2 \times$ higher odds of fetched milkings for lame cows than for sound cows. Perhaps due to their smaller sample size for refusal and fetching observations, Miguel-Pacheco et al. (2014) did not observe any differences in frequencies of refusals or fetched milkings.

For cows milked by an AMS, when accounting for DIM and parity, milk temperature began to increase starting $5 \mathrm{~d}$ before diagnosis of hoof disorders, whereas BW began to decrease starting $4 \mathrm{~d}$ before diagnosis (King et al., 2017b). New cases of lameness in AMS were generally associated with lower milk yield, rumination time, milk temperature, supplement intake, and milking and refusal frequencies compared with healthy cows; for lame cows, milk temperature was the only variable that deviated negatively from the baseline trajectory, accounting for parity and DIM (King et al., 2018).

Caveats to note regarding discrepancies within and between studies include those that controlled for DIM but did not necessary balance lame and sound groups (Almeida et al., 2008); those that excluded cows $<40$ DIM (Van Hertem et al., 2013), a period when illness is most likely; and those that excluded cows with moderate lameness (locomotion score of 2 out of 5 ) and parity $>2$ (Garcia et al., 2014). Some researchers have analyzed cows with lameness and other health disorders (2 of 14 cases in King et al., 2017b), whereas others excluded cases of more than one health disorder (Steensels et al., 2017a); the first scenario is problematic if the other disorder affected variables of interest, and neither scenario allows for differentiation between types of illness. There is also variation between studies regarding the types of comparisons made, whether between lame and sound animals or within lame cows, as well as whether data were analyzed relative to the day of calving or to the day of diagnosis. Nonetheless, clear changes in behavior and productivity are associated with lameness that can be used to earlier detect, if not predict, lameness. Future studies should work to incorporate data representing the whole herd (i.e., fresh cows, all lactation groups, and other illnesses).

\section{Other Health Disorders: Associations with Behavior and Production in AMS and Conventional Herds}

Table 2 highlights the main changes in behavior and productivity associated with illness in conventional milking systems and AMS. General trends for activity, rumination time, and milk yield are consistent between studies, whether comparing sick and healthy animals, or looking within affected cows relative to diagnosis day.

In conventional herds, Steensels et al. (2017a) found reductions in milk yield, rumination time, and activity beginning $5 \mathrm{~d}$ before diagnosis of several disorders. Milk yield declined 1 to $2 \mathrm{~d}$ before diagnosis of milk fever, udder edema, ketosis, and systemic mastitis; $4 \mathrm{~d}$ before puerperal metritis, digestive disorders, hock lesions, and recurrence of hock lesions or digestive disorders; and $5 \mathrm{~d}$ before foot lesions, chronic metritis, recurrence of ketosis, mastitis, or diarrhea (Bareille et al., 2003). In another study, milk yield declined 1 to $2 \mathrm{~d}$ before milk fever, edema, mastitis, and hoof treatments; 4 to 9 $\mathrm{d}$ before digestive disorders, pneumonia, lameness, and abscess; and $\geq 10 \mathrm{~d}$ before going off feed or developing ketosis or metritis (Lukas et al., 2009). In the latter study, milk conductivity also increased 1 to $3 \mathrm{~d}$ before milk fever, DA, edema, mastitis, lameness, and RP; and 6 to $9 \mathrm{~d}$ before pneumonia, off feed, and ketosis. Soriani et al. (2012) grouped cows by their precalving rumination time; compared with cows with high precalving rumination time, cows with lower rumination time before calving maintained that lower rumination time after calving and had a higher incidence of clinical disease (retained placenta, mastitis, ketosis, metritis, DA, and lameness).

Before metabolic disorders specifically, activity (steps/d) began to decline $9 \mathrm{~d}$ before ketosis, DA, and digestive disorders; and milk yield began to drop $5 \mathrm{~d}$ before diagnosis (Edwards and Tozer, 2004). Stangaferro et al. (2016a) reported reductions in rumination time and activity occurring 1 to $5 \mathrm{~d}$ before diagnosis of metabolic disorders. After inducing subacute ruminal acidosis, DeVries et al. (2009) found that rumination time declined by $>1.5 \mathrm{~h} / \mathrm{d}$. Although Goldhawk et al. (2009) did not observe differences in milk yield between healthy cows and those with SCK (serum BHB concentrations $\geq 1.0 \mathrm{mmol} / \mathrm{L}$ during wk 1 postcalving), Gáspárdy et al. (2014) reported a negative deviation in milk yield and rumination time with onset of SCK (unknown diagnosis criteria). Associations of SCK with rumination time and activity before and after calving vary by study. Liboreiro et al. (2015) found no rumination or activity differences precalving $(\mathrm{BHB}>1.0 \mathrm{mmol} / \mathrm{L}$ during wk 1-3 postcalving), but those authors found postcalving reductions in rumination time up to 80 $\mathrm{min} / \mathrm{d}$ and in activity up to 110 daily units. In contrast, Schirmann et al. (2016) saw no differences postcalving and only observed $1 \mathrm{~h} / \mathrm{d}$ lower rumination times before calving for cows that later had SCK after calving (BHB $\geq 1.2 \mathrm{mmol} / \mathrm{L}$ during the first $14 \mathrm{~d}$ ). On the other hand, Kaufman et al. (2016) reported that multiparous cows with SCK (BHB >1.2 mmol/L during wk 1-4 postcalv- 
Table 2. Associations of illness with variables of interest in conventional and automatic milking system (AMS) herds ${ }^{1}$

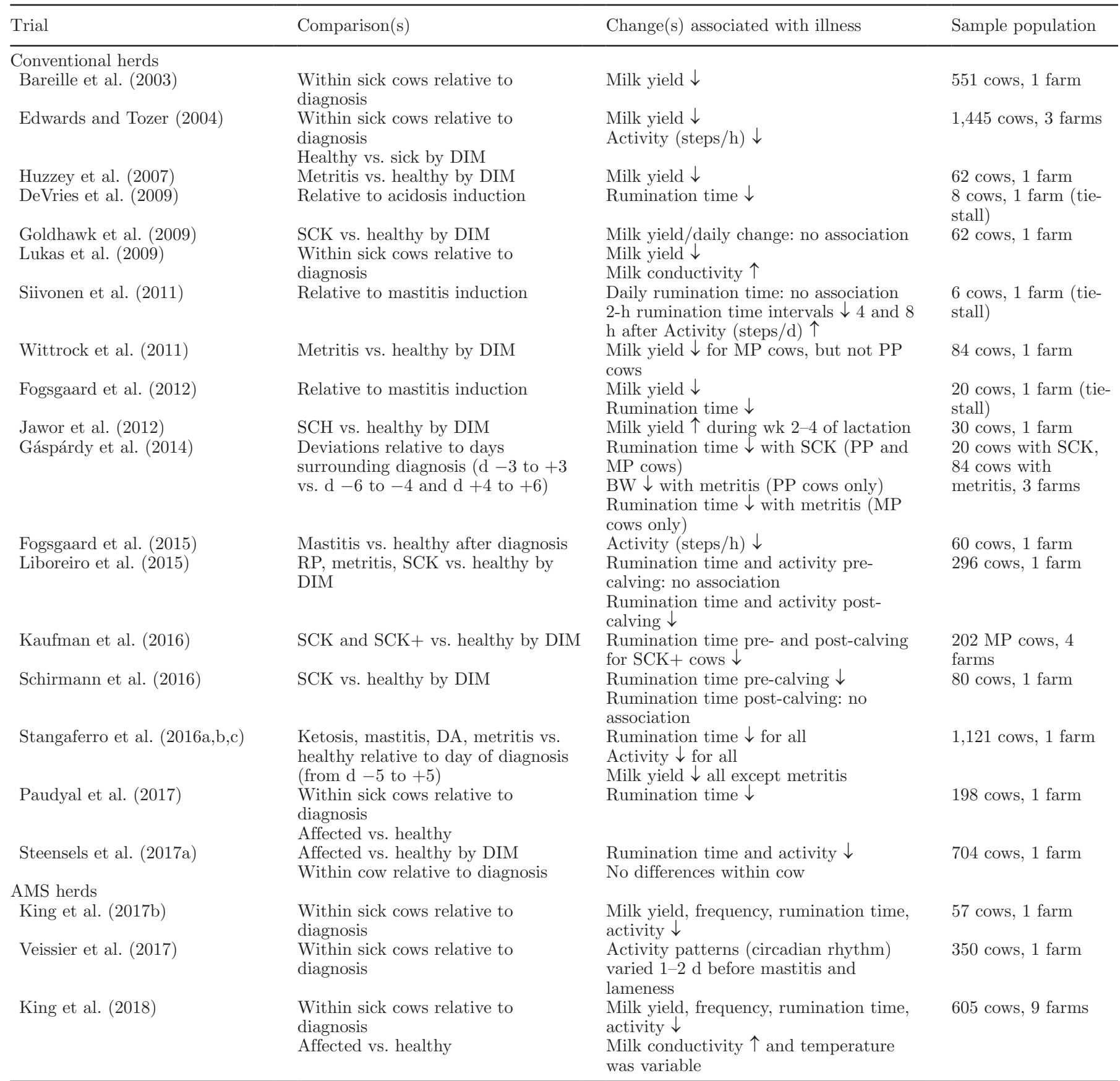

${ }^{1}$ Freestall housing unless specified otherwise; $\mathrm{MP}=$ multiparous, $\mathrm{PP}=$ primiparous, $\mathrm{DD}=$ digestive disorders, $\mathrm{SCK}=$ subclinical ketosis, $\mathrm{SCK}+$ $=$ SCK plus another health disorder, $\mathrm{SCH}=$ subclinical hypocalcemia, $\mathrm{RP}=$ retained placenta, $\mathrm{DA}=$ displaced abomasum.

ing) and another health disorder spent 50 and $90 \mathrm{~min} / \mathrm{d}$ less time ruminating, respectively, pre- and postcalving compared with healthy multiparous cows.

Numerous researchers have documented changes associated with metritis in conventional herds (Paudyal et al., 2017), with varying degrees of response in milk yield, BW, rumination time, and activity based on the severity of metritis (Huzzey et al., 2007; Stangaferro et al., 2016c); results also differed by parity, but overall the trends were similar looking at days preceding and following illness (Gáspárdy et al., 2014). Researchers studying naturally occurring mastitis (Stangaferro et al., 2016b; Paudyal et al., 2017) and those cases induced using an endotoxin (Siivonen et al., 2011; Fogsgaard et 
al., 2012) have documented reductions in rumination time, milk yield, and activity leading up to the day of diagnosis or induction, ranging from 2 to $7 \mathrm{~h} / \mathrm{d}$ rumination time (Paudyal et al., 2017).

To summarize the changes in behavior and productivity with illness in AMS herds, we have included the only 3 articles we are aware of, which are consistent with reports in conventional herds. King et al. (2017b) examined numerous variables from 56 cases of illness in 1 herd relative to the day of diagnosis (d 0) for each illness separately. Always controlling for DIM and parity in their models, they assessed deviations relative to the baseline trajectory of cows affected with a specific disorder. Deviations in milk yield began 4 to $5 \mathrm{~d}$ before DA, pneumonia, and SCK diagnoses by 1.2 to $4.4 \mathrm{~kg} / \mathrm{d}$ each day until $\mathrm{d}-1$, with a total reduction of 4.8 to $13.2 \mathrm{~kg} / \mathrm{d}$. Rumination time began to decline 5 to $8 \mathrm{~d}$ before DA, pneumonia, and SCK diagnoses by 25 to 50 $\mathrm{min} / \mathrm{d}$ each $\mathrm{d}$ until $\mathrm{d}-1$, with a total reduction of 2 to $5 \mathrm{~h} / \mathrm{d}$. Similarly, activity reductions began 4 to $7 \mathrm{~d}$ before diagnoses of DA, pneumonia, SCK, and metritis by 20 to $40 \%$ total, and BW reductions began 4 to 6 $\mathrm{d}$ before pneumonia, SCK, hoof disorders, and metritis diagnoses by 10 to $14 \mathrm{~kg} / \mathrm{d}$ each day. Only before DA, in that study, did milk temperature deviate $6 \mathrm{~d}$ before diagnosis (King et al., 2017b). The key finding in the King et al. (2017b) study was the consistent response of rumination time deviating at least $1 \mathrm{~d}$ before milk yield, on average, but that study also observed large variation between cows. In their follow-up study, with 605 cows in 9 herds, deviations were generally consistent (King et al., 2018). Comparisons were also made with a healthy group of cows given a mock day of diagnosis, from which sick cows often differed even 2 wk before diagnosis (King et al., 2018). Additional trends observed in that study included deviations from baseline milking frequency and milk conductivity occurring 8 and $12 \mathrm{~d}$ before diagnosis of mastitis, respectively. A contradictory result was that only the milk temperature of lame cows deviated from baseline and not cows with DA. The overall message from that work was that acute health disorders (i.e., DA and mastitis) were associated with deviations from those cows' baseline AMS data, whereas more chronic disorders (i.e., SCK and lameness) were associated with significant, but subtle, longer-term changes in milk production and behavior. Finally, Veissier et al. (2017) noted that the circadian activity of cows varied 1 to $2 \mathrm{~d}$ before diagnosis of lameness and mastitis.

It would be interesting to compare behavioral responses to health disorders in both conventional and AMS herds. With the current data available, however, we cannot determine whether responses to lameness and illness are augmented in AMS. Furthermore, varia- tion may exist between housing systems (bedded pack vs. freestall) and traffic type (forced vs. free). Therefore, more research is needed to collect information on large samples of cows from many farms of diverse barn designs and management practices.

\section{HEALTH MANAGEMENT SOFTWARE AND DETECTION MODELS}

A key feature of AMS is data collection and subsequent generation of management reports and alert lists. Data can be used to create management reports and task lists, as well as attention lists of cows with potential health problems. These reports can overwhelm producers with excessive alerts (false positives), while not necessarily being sensitive enough to pick up chronic disorders (false negatives). Thus, these data must be transformed into useful, reliable information for producers, using field experience and science-based recommendations. Despite some inconsistencies in the literature, the potential certainly exists to combine the use of several behavior and production variables to create highly sensitive and specific health detection models. The goal should be to achieve $99 \%$ specificity and $80 \%$ sensitivity, as recommended by the International Organization for Standardization, to evaluate model performance for automated detection of abnormal milk (i.e., Rutten et al., 2013). Additionally, illness detection software should include adjustable settings to personalize specificity and sensitivity based on each farmer's management strategy, such as how willing they are to take risks weighted against the time needed to visually assess flagged cows that may not actually be sick.

Alerts created by AMS manufacturers are currently available on-farm but do not always incorporate validated models and algorithms using data from validated technologies. These reports include a mastitis detection index and a milking performance index (teat attachment speed) for herds with the DeLaval system (DelPro; DeLaval International AB, Tumba, Sweden). Herd Navigator (DeLaval International AB) measures lactate dehydrogenase for mastitis detection, milk BHB for ketosis detection, and milk progesterone for heat detection and pregnancy. Lely's T4C software (Time-for-Cows, Lely Industries N.V., Maassluis, the Netherlands) has milk, estrus, and rumination attention lists, which flag cows with deviations in milk yield, cell count, conductivity, and temperature, BW, activity, and rumination time. Within the last few years, Lely has released a sick cow report, which uses a combination of these variables. Although these metrics and commercial alerts have great potential to aid in illness detection, they have not been fully validated (or this has not been done so transparently); that is, peer-reviewed and publicly 
available scientific validation is not available. Nonetheless, many of these alerts are already in use in the field.

The same variables used in commercial health alerts have been incorporated into various detection models created and validated by researchers. Stangaferro et al. (2016a,b,c) assessed the validity of a health index score, composed of rumination and activity data during a 5-d period before diagnosis, in a conventional herd. The index achieved a sensitivity of $98 \%$ for DA, $91 \%$ for ketosis, $89 \%$ for indigestion, and $93 \%$ for those 3 disorders combined (Stangaferro et al., 2016a). Sensitivity for all cases of clinical mastitis and metritis was 58 and $55 \%$, respectively; although this was similar for cases of only mastitis (55\%) or metritis (53\%), sensitivity was greater for cows with mastitis and another health disorder (89\%), and for cows with metritis and another disorder (78\%; Stangaferro et al., 2016b,c). The index was most sensitive for cases of Escherichia coli mastitis $(81 \%)$ and less so for gram-positive cases of mastitis (45 to $48 \%$ ) and less severe cases of metritis (Stangaferro et al., 2016b,c). Considering all health disorders studied, those researchers reported an overall sensitivity of $59 \%$ and specificity of $98 \%$ for the health index score.

Steensels et al. (2016) used a decision tree model to detect ketosis and metritis in AMS-milked cows. With a specificity of $87 \%$ and sensitivity of $69 \%$, their model considered rumination time and activity (measured by neck collar monitors), as well as milk yield, milk slope, and current $\mathrm{BW}$ relative to $\mathrm{BW}$ at calving (measured by AMS) to predict the probability of illness for each animal. It is unclear, however, which cows were considered healthy in that study, or whether cows with other disorders were excluded from the analysis. Those authors also evaluated a ketosis prediction model on 4 different farms (Steensels et al., 2017b), finding that its sensitivity (78-90\%) and specificity (71-74\%) were improved when running model training and validation within the same herd. However, Steensels et al. (2017b) and Stangaferro et al. (2016a,b,c) excluded cows with multiple health disorders. Therefore, limitations remain with current prediction models regarding how to deal with cases of more than one illness and how to detect one illness without excluding the others from analyses.

Regarding lameness detection, Garcia et al. (2014) created models using activity (measured by neck collar monitors), milk flow, and teat cup attachment data from $1 \mathrm{wk}$ before and after lameness diagnosis in an AMS herd. Separate models were created for first- and second-lactation cows, which had reported specificities of 77 and $83 \%$, respectively, and both had a sensitivity of $79 \%$. Using a model combining several activity variables (i.e., number of steps negatively associated with lameness, and lying behavior data with various associations, measured by leg band accelerometers), milk yield per day ( $\geq 3$ negative outliers/week), and concentrate leftovers per day (positively associated with lameness), de Mol et al. (2013) created a model with high sensitivity (85.5\%) and specificity (88.8\%) for identifying lameness on the same day as diagnosis in an AMS herd. Those 2 studies, however, did not include cows with an uneven gait that did not obviously favor one limb, which made up almost $50 \%$ of their observations; the difference between those and lame cows can be subtle, and those authors recognized this data exclusion as a large limitation of their study. Van Hertem et al. (2013) also created a lameness detection model, which used milk yield, activity, and rumination data from 4 to $7 \mathrm{~d}$ before diagnosis in a parlor-milked herd. Those authors reported a sensitivity of $89 \%$ and specificity of $86 \%$, finding that lame cows produced less milk, were proportionately less active during the day, and spent less time ruminating at night compared with sound cows. Other researchers have incorporated similar variables into lameness detection models, such as BW, activity, milk order, walking speed, standing bouts, lying time, and limb weight ratio during milking (Kamphuis et al., 2013a; Beer et al., 2016; Nechanitzky et al., 2016); however, those researchers excluded cows affected by health disorders other than lameness, which would reduce their false positive rates, and, in 2 studies, fresh cows $<30$ to 40 DIM (when many other health disorders arise) were excluded. Using cow activity and wavelet analysis, Miekley et al. (2012) created lameness detection models with 40 to $64 \%$ sensitivity, 72 to $85 \%$ specificity, and high error rates $(>90 \%)$.

For credibility, accuracy, and repeatability, sciencebased recommendations are needed to generate health attention reports and to select settings for on-farm application, such as the recent development (Kamphuis et al., 2013b) and field validation (Kamphuis et al., 2016) of an inline detection system for mastitis and high SCC; those researchers also consulted industry representatives for feedback to improve the application of those models. To briefly touch on mastitis detection in conventional milking systems, Miekley et al. (2013a) achieved $85 \%$ sensitivity and 72 to $83 \%$ specificity when detecting mastitis using deviations from 5 -d moving averages and standard deviations of milk yield and conductivity. In similar studies, Miekley et al. (2012, 2013b) used milk yield and conductivity to detect mastitis using principal components and wavelet analyses and concluded that these methods were not ready for on-farm application. In AMS herds, Sørensen et al. (2016) evaluated online SCC data to identify elevated risk of mastitis in AMS. By modifying 2 reports available with that software, they tested various validation scenarios; based on new alerts, those models achieved sensitivities of 28 to $43 \%$ and specificities $>99 \%$, but 
they achieved much higher sensitivities when validating based on cows that appeared on the intramammary infection report (55-89\%). Those authors are currently working toward the highly desired integration of information to help with decision-making and monitoring.

\section{FUTURE DIRECTIONS}

Remaining gaps in knowledge are how to best identify cows with lameness or other health disorders in AMS herds using a combination of rumination, activity, and milk data, especially for early lactation animals. Different variations (e.g., standard deviation, relative change) and weightings of each variable may also prove useful. Such a multivariate approach may enhance the performance of illness detection models (Miekley et al., $2012,2013 b)$. Not only may health alerts notify producers of potential issues, but those alerts could indicate the probability and type of problem as well. This could even be a general category of illness; that is, metabolic versus infectious, internally versus externally caused, or acute versus state-like.

Of the current studies that have worked toward disease detection, many data have been excluded or separated for isolated models (i.e., fresh cows, multiple lactation groups, and cows with multiple illnesses or moderate cases). Thus, future studies should incorporate data from the entire lactating herd and should consider, and account for, parity and stage of lactation or DIM of each animal, regardless of whether they retain those variables in final algorithms. Researchers have previously controlled for parity (King et al., 2017b) or even created different models for parity groups, finding activity data to be more informative for primiparous cows and less informative for second-lactation cows (Garcia et al., 2014). King et al. (2017b) found differences in slope estimates when accounting for DIM, whereas Garcia et al. (2014) saw no improvements in their models when they included DIM.

Researchers have examined, and should continue to investigate, deviations within sick cows as an average (King et al., 2018) or individually (Paudyal et al., 2017). Potentially most importantly, cows with illness should be compared with a group of healthy contemporaries (Stangaferro et al., 2016a,b,c; Paudyal et al., 2017; King et al., 2018), which could refine the ability of detection models to identify subtle deviations in early lactation.

Finally, attention should be given to creating separate models for dry cows and young stock. It is likely that, as in lactating cows, the activity or behavior of those animals will respond before production variables begin to decline (Edwards and Tozer, 2004; King et al., 2017b, 2018), including growth, body condition, or allo- cation of resources to a developing fetus. We encourage manufacturers and software makers to make (at least some of) their algorithm components publicly available to aid independent researchers in understanding and improving upon those methods.

\section{CONCLUSIONS}

This review summarizes 2 decades of research regarding the effects of health disorders on cow behavior and production, and the resultant use of those variables to help detect illness. Compared with behaviors in healthy cows, consistent trends are observed in activity, rumination time, and milk yield leading up to diagnosis of health disorders, except for lameness, which may not necessarily alter rumination time or activity. To advance this technology, it is necessary for commercial software to incorporate validated models and algorithms for generating health alerts on-farm. Future studies should (1) incorporate the entire lactating herd while accounting for stage of lactation and parity of each animal; (2) evaluate the deviations that cows exhibit from their own baseline trajectories and relative to healthy contemporaries; (3) combine the use of several variables into health alerts; and (4) differentiate the probable type of health disorder.

\section{ACKNOWLEDGMENTS}

Meagan King was financially supported in part by the Canada First Research Excellence Fund (Ottawa, ON, Canada) and by a contribution from the Dairy Research Cluster II Initiative, funded by the Dairy Farmers of Canada (Ottawa, ON, Canada), Agriculture and Agri-Food Canada (Ottawa, ON, Canada), the Canadian Dairy Network (Guelph, ON, Canada), and the Canadian Dairy Commission (Ottawa, ON, Canada).

\section{REFERENCES}

Almeida, P. E., P. S. D. Weber, J. L. Burton, and A. J. Zanella. 2008. Depressed DHEA and increased sickness response behaviors in lame dairy cows with inflammatory foot lesions. Domest. Anim. Endocrinol. 34:89-99. https://doi.org/10.1016/j.domaniend.2006 .11 .006 .

Bach, A., M. Dinarés, M. Devant, and X. Carré. 2007. Associations between lameness and production, feeding and milking attendance of Holstein cows milked with an automatic milking system. J. Dairy Res. 74:40-46. https://doi.org/10.1017/S0022029906002184.

Bareille, N., F. Beaudeau, S. Billon, A. Robert, and P. Faverdin. 2003. Effects of health disorders on feed intake and milk production in dairy cows. Livest. Prod. Sci. 83:53-62. https://doi.org/10.1016/ S0301-6226(03)00040-X.

Barkema, H. W., M. A. G. von Keyserlingk, J. P. Kastelic, T. J. G. M. Lam, C. Luby, J.-P. Roy, S. J. LeBlanc, G. P. Keefe, and D. F. Kelton. 2015. Invited review: Changes in the dairy industry affecting dairy cattle health and welfare. J. Dairy Sci. 98:7426-7445. https://doi.org/10.3168/jds.2015-9377. 
Beer, G., M. Alsaaod, A. Starke, G. Schuepbach-Regula, H. Mülller, P. Kohler, and A. Steiner. 2016. Use of extended characteristics of locomotion and feeding behavior for automated identification of lame dairy cows. PLoS One 11:e0155796. https://doi.org/10.1371/ journal.pone.0155796.

Bicalho, R. C., L. D. Warnick, and C. L. Guard. 2008. Strategies to analyze milk losses caused by diseases with potential incidence throughout the lactation: A lameness example. J. Dairy Sci. 91:2653-2661. https://doi.org/10.3168/jds.2007-0744.

Borchers, M. R., and J. M. Bewley. 2015. An assessment of producer precision dairy farming technology use, prepurchase considerations, and usefulness. J. Dairy Sci. 98:4198-4205. https://doi .org $/ 10.3168 /$ jds.2014-8963.

Borderas, T. F., A. Fournier, J. Rushen, and A. M. B. de Passillé. 2008. Effect of lameness on dairy cows' visits to automatic milking systems. Can. J. Anim. Sci. 88:1-8. https://doi.org/10.4141/ CJAS07014.

de Mol, R. M., G. André, E. J. B. Bleumer, J. T. N. van der Werf, Y. de Haas, and C. G. van Reenen. 2013. Applicability of day-to-day variation in behavior for the automated detection of lameness in dairy cows. J. Dairy Sci. 96:3703-3712. https://doi.org/10.3168/ jds.2012-6305.

Deming, J. A., R. Bergeron, K. E. Leslie, and T. J. DeVries. 2013. Associations of cow-level factors, frequency of feed delivery, and standing and lying behaviour of dairy cows milked in an automatic system. Can. J. Anim. Sci. 93:427-433. https://doi.org/10.4141/ CJAS2013-055.

DeVries, T. J., K. A. Beauchemin, F. Dohme, and K. S. SchwartzkopfGenswein. 2009. Repeated ruminal acidosis challenges in lactating dairy cows at high and low risk for developing acidosis: Feeding, ruminating, and lying behavior. J. Dairy Sci. 92:5067-5078. https://doi.org/10.3168/jds.2009-2102.

Edwards, J. L., and P. R. Tozer. 2004. Using activity and milk yield as predictors of fresh cow disorders. J. Dairy Sci. 87:524-531. https:// doi.org/10.3168/jds.S0022-0302(04)73192-6.

Fogsgaard, K. K., T. W. Bennedsgaard, and M. S. Herskin. 2015. Behavioral changes in freestall-housed dairy cows with naturally occurring clinical mastitis. J. Dairy Sci. 98:1730-1738. https://doi .org/10.3168/jds.2014-8347.

Fogsgaard, K. K., C. M. Røntved, P. Sørensen, and M. S. Herskin. 2012. Sickness behavior in dairy cows during Escherichia coli mastitis. J. Dairy Sci. 95:630-638. https://doi.org/10.3168/jds.2011 -4350 .

Garcia, E., I. Klaas, J. M. Amigo, R. Bro, and C. Enevoldsen. 2014. Lameness detection challenges in automated milking systems addressed with partial least squares discriminant analysis. J. Dairy Sci. 97:7476-7486. https://doi.org/10.3168/jds.2014-7982.

Gáspárdy, A., G. Efrat, A. C. Bajcsy, and S. G. Fekete. 2014. Electronic monitoring of rumination activity as an indicator of health status and production traits in high-yielding dairy cows. Acta Vet. Hung. 62:452-462. https://doi.org/10.1556/AVet.2014.026.

Goldhawk, C., N. Chapinal, D. M. Veira, D. M. Weary, and M. A. G. von Keyserlingk. 2009. Prepartum feeding behavior is an early indicator of subclinical ketosis. J. Dairy Sci. 92:4971-4977. https:// doi.org/10.3168/jds.2009-2242.

Green, L. E., V. J. Hedges, Y. H. Schukken, R. W. Blowey, and A. J. Packington. 2002. The impact of clinical lameness on the milk yield of dairy cows. J. Dairy Sci. 85:2250-2256. https://doi.org/10 .3168/jds.S0022-0302(02)74304-X.

Hogeveen, H., C. Kamphuis, W. Steeneveld, and H. Mollenhorst. 2010. Sensors and clinical mastitis - The quest for the perfect alert. Sensors (Basel) 10:7991-8009. https://doi.org/10.3390/s100907991.

Huzzey, J. M., D. M. Veira, D. M. Weary, and M. A. G. von Keyserlingk. 2007. Prepartum behavior and dry matter intake identify dairy cows at risk for metritis. J. Dairy Sci. 90:3220-3233. https:// doi.org/10.3168/jds.2006-807.

Jacobs, J. A., and J. M. Siegford. 2012. Invited review: The impact of automatic milking systems on dairy cow management, behavior, health, and welfare. J. Dairy Sci. 95:2227-2247. https://doi.org/ 10.3168/jds.2011-4943
Jawor, P. E., J. M. Huzzey, S. J. LeBlanc, and M. A. G. von Keyserlingk. 2012. Associations of subclinical hypocalcemia at calving with milk yield, and feeding, drinking, and standing behaviors around parturition in Holstein cows. J. Dairy Sci. 95:1240-1248. https://doi.org/10.3168/jds.2011-4586.

Kamphuis, C., B. Dela Rue, G. Mein, and J. Jago. 2013b. Development of protocols to evaluate in-line mastitis-detection systems. J. Dairy Sci. 96:4047-4058. https://doi.org/10.3168/jds.2012-6190.

Kamphuis, C., B. T. Dela Rue, and C. R. Eastwood. 2016. Field validation of protocols developed to evaluate in-line mastitis detection systems. J. Dairy Sci. 99:1619-1631. https://doi.org/10.3168/jds .2015-10253.

Kamphuis, C., E. Frank, J. K. Burke, G. A. Verkerk, and J. G. Jago. 2013a. Applying additive logistic regression to data derived from sensors monitoring behavioral and physiological characteristics of dairy cows to detect lameness. J. Dairy Sci. 96:7043-7053. https:// doi.org/10.3168/jds.2013-6993.

Kaufman, E. I., S. J. LeBlanc, B. W. McBride, T. F. Duffield, and T. J. DeVries. 2016. Association of rumination time with subclinical ketosis in transition dairy cows. J. Dairy Sci. 99:5604-5618. https://doi.org/10.3168/jds.2015-10509.

King, M. T. M., K. M. Dancy, S. J. LeBlanc, E. A. Pajor, and T. J. DeVries. 2017b. Deviations in behavior and productivity data before diagnosis of health disorders in cows milked with an automated system. J. Dairy Sci. 100:8358-8371. https://doi.org/10 $.3168 /$ jds.2017-12723.

King, M. T. M., K. M. Dancy, S. J. LeBlanc, E. A. Pajor, and T. J. DeVries. 2018. Behavior and productivity of cows milked in automated systems prior to diagnosis of health disorders in early lactation. J. Dairy Sci. 101:4343-4356. https://doi.org/10.3168/ jds.2017-13686.

King, M. T. M., S. J. LeBlanc, E. A. Pajor, and T. J. Devries. 2017a. Cow-level associations of lameness, behavior, and milk yield of cows milked in automated systems. J. Dairy Sci. 100:4818-4828. https://doi.org/10.3168/jds.2016-12281.

Liboreiro, D. N., K. S. Machado, P. R. B. Silva, M. M. Maturana, T. K. Nishimura, A. P. Brandão, M. I. Endres, and R. C. Chebel. 2015. Characterization of peripartum rumination and activity of cows diagnosed with metabolic and uterine diseases. J. Dairy Sci. 98:6812-6827. https://doi.org/10.3168/jds.2014-8947.

Lukas, J. M., J. K. Reneau, R. Wallace, D. Hawkins, and C. MunozZanzi. 2009. A novel method of analyzing daily milk production and electrical conductivity to predict disease onset. J. Dairy Sci. 92:5964-5976. https://doi.org/10.3168/jds.2009-2066.

Miekley, B., I. Traulsen, and J. Krieter. 2012. Detection of mastitis and lameness in dairy cows using wavelet analysis. Livest. Sci. 148:227-236. https://doi.org/10.1016/j.livsci.2012.06.010.

Miekley, B., I. Traulsen, and J. Krieter. 2013a. Mastitis detection in dairy cows: The application of support vector machines. J. Agric. Sci. 151:889-897. https://doi.org/10.1017/S0021859613000178.

Miekley, B., I. Traulsen, and J. Krieter. 2013b. Principal component analysis for the early detection of mastitis and lameness in dairy cows. J. Dairy Res. 80:335-343. https://doi.org/10.1017/ S0022029913000290.

Miguel-Pacheco, G. G., J. Kaler, J. Remnant, L. Cheyne, C. Abbott, A. P. French, T. P. Pridmore, and J. N. Huxley. 2014. Behavioural changes in dairy cows with lameness in an automatic milking system. Appl. Anim. Behav. Sci. 150:1-8. https://doi.org/10.1016/j applanim.2013.11.003.

Nechanitzky, K., A. Starke, B. Vidondo, H. Müller, M. Reckardt, K. Friedli, and A. Steiner. 2016. Analysis of behavioral changes in dairy cows associated with claw horn lesions. J. Dairy Sci. 99:2904-2914. https://doi.org/10.3168/jds.2015-10109.

Paudyal, S., F. P. Maunsell, J. T. Richeson, C. A. Risco, D. A. Donovan, and P. J. Pinedo. 2017. Rumination time and monitoring of health disorders during early lactation. Animal 12:1484-1492. https://doi.org/10.1017/S1751731117002932.

Russell, R. A., and J. M. Bewley. 2013. Characterization of Kentucky dairy producer decision-making behavior. J. Dairy Sci. 96:47514758. https://doi.org/10.3168/jds.2012-6538. 
Rutten, C. J., A. G. J. Velthuis, W. Steeneveld, and H. Hogeveen. 2013. Invited review: sensors to support health management on dairy farms. J. Dairy Sci. 96:1928-1952. https://doi.org/10.3168/ jds.2012-6107.

Schirmann, K., D. M. Weary, W. Heuwieser, N. Chapinal, R. L. A. Cerri, and M. A. G. von Keyserlingk. 2016. Short communication: Rumination and feeding behaviors differ between healthy and sick dairy cows during the transition period. J. Dairy Sci. 99:99179924. https://doi.org/10.3168/jds.2015-10548.

Siivonen, J., S. Taponen, M. Hovinen, M. Pastell, B. J. Lensink, S. Pyörälä, L. Hänninen, K. K. Fogsgaard, C. M. Røntved, P. S $\varnothing-$ rensen, M. S. Herskin, D. B. Haley, J. Rushen, and A. M. De Passillé. 2011. Impact of acute clinical mastitis on cow behaviour. Can. J. Anim. Sci. 80:257-263. https://doi.org/10.4141/A99-084.

Singh, Y., S. S. Lathwal, A. K. Chakravarty, A. K. Gupta, T. K. Mohanty, T. V. Raja, R. L. Dangi, and B. K. Roy. 2011. Effect of lameness (hoof disorders) on productivity of Karan Fries crossbred cows. Anim. Sci. J. 82:169-174. https://doi.org/10.1111/j.1740 $-0929.2010 .00800 . x$

Sørensen, L. P., M. Bjerring, and P. Løvendahl. 2016. Monitoring individual cow udder health in automated milking systems using online somatic cell counts. J. Dairy Sci. 99:608-620. https://doi .org/10.3168/jds.2014-8823.

Soriani, N., E. Trevisi, and L. Calamari. 2012. Relationships between rumination time, metabolic conditions, and health status in dairy cows during the transition period. J. Anim. Sci. 90:4544-4554. https://doi.org/10.2527/jas.2012-5064.

Stangaferro, M., R. Wijma, C. Quinteros, M. Medrano, M. Masello, and J. Giordano. 2016a. Use of a rumination and activity monitoring for the identification of dairy cows with health disorders: Part II. Mastitis. J. Dairy Sci. 99:7411-7421. https://doi.org/10.3168/ jds.2016-10908.

Stangaferro, M. L., R. Wijma, C. Quinteros, M. Medrano, M. Masello, and J. Giordano. 2016b. Use of a rumination and activity monitoring for the identification of dairy cows with health disorders: Part III. Metritis. J. Dairy Sci. 99:7422-7433. https://doi.org/10.3168/ jds.2016-11352.

Stangaferro, M. L., R. Wijma, C. Quinteros, M. Medrano, M. Masello, and J. Giordano. 2016c. Use of a rumination and activity monitoring for the identification of dairy cows with health disorders: Part I. Metabolic and digestive disorders. J. Dairy Sci. 99:7395-7410. https://doi.org/10.3168/jds.2016-10907.
Steensels, M., A. Antler, C. Bahr, D. Berckmans, E. Maltz, and I Halachmi. 2016. A decision-tree model to detect post-calving diseases based on rumination, activity, milk yield, BW and voluntary visits to the milking robot. Animal 10:1493-1500. https://doi.org/ 10.1017/S1751731116000744

Steensels, M., E. Maltz, C. Bahr, D. Berckmans, A. Antler, and I. Halachmi. 2017a. Towards practical application of sensors for monitoring animal health: the effect of post-calving health problems on rumination duration, activity and milk yield. J. Dairy Res. 84:132-138. https://doi.org/10.1017/S0022029917000176.

Steensels, M. E. Maltz, C. Bahr, D. Berckmans, A. Antler, and I. Halachmi. 2017b. Towards practical application of sensors for monitoring animal health; design and validation of a model to detect ketosis. J. Dairy Res. 84:139-145. https://doi.org/10.1017/ S0022029917000188.

Tse, C., H. W. Barkema, T. J. Devries, J. Rushen, and E. A. Pajor. 2017. Effect of transitioning to automatic milking systems on producers' perceptions of farm management and cow health in the Canadian dairy industry. J. Dairy Sci. 100:2404-2414. https://doi .org/10.3168/jds.2016-11521.

Van Hertem, T., E. Maltz, A. Antler, C. E. B. Romanini, S. Viazzi, C. Bahr, A. Schlageter-Tello, C. Lokhorst, D. Berckmans, and I. Halachmi. 2013. Lameness detection based on multivariate continuous sensing of milk yield, rumination, and neck activity. J. Dairy Sci. 96:4286-4298. https://doi.org/10.3168/jds.2012-6188.

Veissier, I., M. M. Mialon, and K. H. Sloth. 2017. Short communication: Early modification of the circadian organization of cow activity in relation to disease or estrus. J. Dairy Sci. 100:3969-3974. https://doi.org/10.3168/jds.2016-11853.

Walker, S. L., R. F. Smith, J. E. Routly, D. N. Jones, M. J. Morris, and H. Dobson. 2008. Lameness, activity time-budgets, and estrus expression in dairy cattle. J. Dairy Sci. 91:4552-4559. https://doi .org/10.3168/jds.2008-1048.

Weigele, H. C., L. Gygax, A. Steiner, B. Wechsler, and J. B. Burla 2018. Moderate lameness leads to marked behavioral changes in dairy cows. J. Dairy Sci. 101:2370-2382. https://doi.org/10.3168/ jds.2017-13120.

Wittrock, J. M., K. L. Proudfoot, D. M. Weary, and M. A. G. von Keyserlingk. 2011. Short communication: Metritis affects milk production and cull rate of Holstein multiparous and primiparous dairy cows differently. J. Dairy Sci. 94:2408-2412. https://doi.org/ 10.3168/jds.2010-3697. 